\title{
Developing a Framework for a New Technical Elective: Prototyping Multi- functional Urban Micro-farms as an Experiential Learning Strategy for Ar- chitecture and Construction Management Students
}

\section{Mr. Eugene Kwak, Farmingdale State College, State University of New York}

Eugene Kwak is a licensed architect and an assistant professor in the Department of Architecture and Construction Management at Farmingdale State College, State University of New York. He has been running research and grant-based projects, including the George Washington Carver Community garden design in New Iberia, Louisiana. During his tenure in the private sector, he focused on technology-based green and sustainable work including the New Housing New York Legacy Project. Eugene's entry for the Intersection: Grand Concourse 100 and Reinventing Grand Army Plaza Competition was selected as one of the top 30 proposals to be included in a public exhibition. As a student at Columbia University, Eugene earned the Lucille Smyser Lowenfish Memorial Prize, which is given to the graduating student whose work is most outstanding. He has taught architectural design, urban design seminars, and various workshops at Parsons The New School, Pratt Institute, and New York Institute of Technology. Eugene received a Bachelor of Architecture from Carnegie Mellon University and a Master of Science Degree in Architecture and Urban Design from Columbia University. 


\title{
Developing a framework for a new technical elective: Prototyping multi- functional urban micro-farms as an experiential learning strategy for Architecture and Construction Management students
}

\begin{abstract}
From the effects of widespread monoculture to the aging population of career farmers, the agriculture industry today is facing myriad challenges. With land becoming more and more scarce, farms today are plagued by a sheer lack of resources, capital, and infrastructure required to distribute and preserve sustainable agriculture. And yet, there has never been more consumer demand for what farmers produce and for innovative agricultural models.

The goal of this research is to develop a framework for a new technical elective in the Department of Architecture and Construction Management that proposes to design and build, with the support of the Urban Horticulture and Design Department, a series of urban micro-farms throughout the campus. When this new technical elective is fully developed, the course aspires to facilitate a hands-on learning experience for the students to apply knowledge obtained from other courses and evolve the discourse around sustainability, particularly concerning the food system. This work-in-progress paper provides an overview of the proposed course, required background research, implementation strategy, and description of the logistics.
\end{abstract}

\section{Introduction}

The current curriculum of the Architecture and Construction Management Department consists of technical and design courses, providing a balance of practical knowledge and creative design outcomes. Non-design courses employ various educational strategies - such as visiting construction sites, conducting lab experiments, observing demonstrations, generating technical drawings, building 3-dimensional models, and watching construction videos - to further strengthen the student learning experience. The students have given positive feedback for visiting a construction site and observing the construction process first-hand. This real-world experience helps students understand the material and assembly of the architectural components, and this cognitive learning process complements the limitations of theoretical learning in a traditional classroom setting.

Architecture and Construction Management students are required to take two courses, Materials and Methods of Construction I and II, during their first year in the program. These non-design courses teach students a wide range of construction methods, assemblies, processes, and material choices. Students in these courses participate actively when they see a demonstration and interact with construction material such as wood studs, light gauge steel frame, and masonry brick. Many students have also shown strong interest in building a full-scale structure, but the 
current curriculum does not offer that opportunity. Frequently in the field of architecture, construction of mock-up, a full-scale model of design, is used to examine the material behavior, appearance, performance, and assembly of the components. Even for a seasoned professional, this process reveals any unforeseen design issues and provides an opportunity to receive feedback. Building a full-scale structure aligns with Applied Learning philosophy, direct application of learned knowledge, and can be utilized as an instructional tool in technical courses.

The author's affiliated school, Farmingdale State College, State University of New York, has an agricultural heritage, rooted back to the founding of the institution as a school of applied agriculture, and this inherited value provides a distinctive strength to formulate this research. The Department of Urban Horticulture and Design has implemented multiple programs and outdoor classrooms to incorporate instructional alignment with campus community outreach. This precedent serves as a benchmark for the course proposal and helps with the preliminary research on the execution. The author had multiple preliminary meetings to initiate collaboration between the two departments.

The Department of Architecture and Construction Management is seeking innovative instructional strategies to strengthen hands-on experience and embed the experiential strategies in the curriculum. This initiative provides a stronger reason for developing a new technical elective and incorporating Applied Learning strategies to augment the student learning experience. The proposed course's aims include community outreach, interdisciplinary learning, and experiential learning as a vehicle to encourage student involvement. The urban micro-farms will incorporate raised beds that double as outdoor furniture and through an iterative design sequence, students will evaluate the process of idea generation, mode of representation, implementation strategy, construction methods, overall design concept, and collaboration with the other disciplines.

\section{Background}

Our population has been relying on local farms for our food every day. And yet, great farms are being threatened daily — by real estate development, by big business agriculture, and by the real financial burden of responsible modern farming. Industrialized farming, for all its virtues, has not come without collateral damage - depleting healthy soil and contributing to threats of contamination. The U.S. is losing farmland at a rate of 40 acres every hour; New York State alone has lost a half million acres over the last 30 years [1]. With the average age of farmers rising and the number of young, new farmers declining at an alarming rate [2], the generational passing of practical, institutional knowledge and experience is at risk. Since the earliest days of civilization, farming has been the bedrock of society. It is imperative for our generation to uphold and support sustainable farming practices and create innovative solutions to the agricultural crisis.

The author was part of a grant-based project with a 501c (3) non-profit community organization in Louisiana, Envision da Berry, which procured startup cost and coordinated volunteer effort to design and build an urban micro-farm in a distressed public housing community. This lowincome community lacked fresh food access, rendering it as a food desert, and the community 
suffered from myriad health-related issues. The design incorporated a hydroponic system for water-based plant growing and a series of raised beds for soil-based plants that double as outdoor furniture to promote community gathering and activities. This project targeted to alleviate food insecurity, provide education for children, and deliver training opportunities for participants to learn urban farming skills. This project ultimately became an effort to combat poverty and to eradicate social inequality by establishing the community garden as a viable revenue stream for the residents. Also, various additional benefits are illustrated by the following list:

- Give residents access to fresh, healthy food

- Reduce residents' monthly food costs

- Improve residents' health

- Create social activities for isolated seniors

- Reduce crime and drug activity

- Teach residents basic vocational skills

- Empower youth and disabled residents

- Encourage residents' self-reliance

- Create income opportunities for residents

- Encourage water conservation, waste reduction, and recycling

- Beautify site grounds

- Increase site and overall area property values

Another aspect of this project that can serve as a benchmark for the research is the volunteer participation during the construction process, exhibited in figures 1.1 through 1.4. College students participated in an Alternative Spring Break program, a project-based volunteer opportunity for students to make a positive contribution to local communities and tackle various challenges. This program allows participants to gain insights and empirical knowledge to apply in the expanded areas of the college experience [3]. One of the student clubs at Farmingdale State College, the Architecture and Construction Technology (ACT) club, can serve as a potential volunteer group during the preliminary research. The ACT club participated in design competitions in the past, and a number of members expressed their interest to volunteer in the research process, as the club seeks to engage in diverse architectural activities to gain experience and knowledge in the industry.

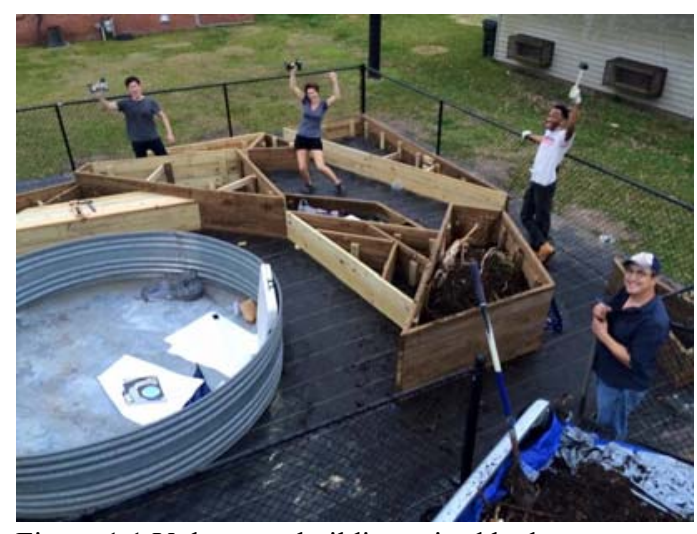

Figure 1.1 Volunteers building raised beds

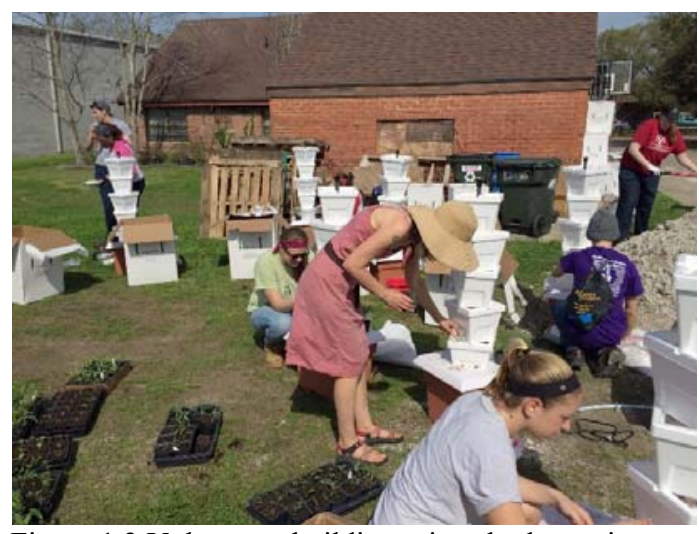

Figure 1.2 Volunteers building micro-hydroponic system 


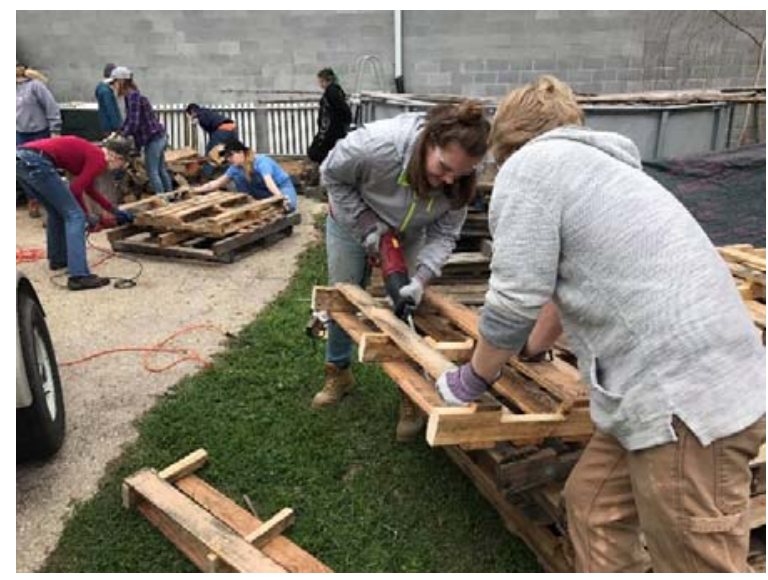

Figure 1.3 Volunteers building micro-farm system prototype

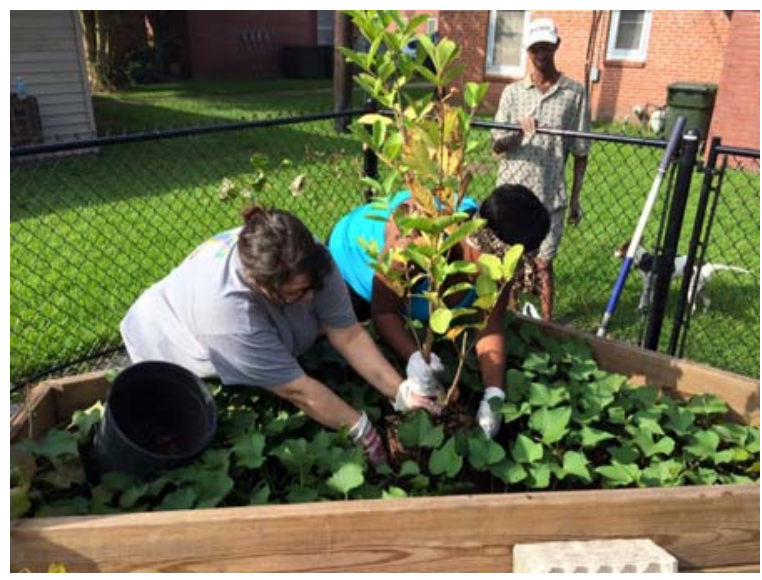

Figure 1.4 Resident volunteers planting

The planning of the project started by procuring startup funds through local grants. The application included a detailed material list and cost analysis as exhibited in Table 1.1. This procurement can serve as a point of reference for the multiple research funding opportunities in connection with course development at Farmingdale State College. The applicable funding includes the Students First Grants, the Applied Learning Development Incentive, and the annual Summer Scholarship Support. The Students First Grants provide support for improving classroom teaching, learning through activities outside of the classroom, and assessment of pedagogies. Applied Learning Development Incentive supports co-curricular activities that allow students to apply knowledge gained traditionally from classrooms to a hands-on and/or real-world setting. Lastly, the annual Summer Scholarship Support provides an opportunity for faculty to conduct preliminary research, develop a framework for a pilot project, develop pedagogical strategies, explore assessment models, and share the research findings with the campus community. Recently, the 2019 Summer Scholarship Support was awarded to the author, and the funding will be used to build a full-scale model and run simulations based on various scenarios with the support of the Department of Urban Horticulture and Design.

\begin{tabular}{|c|c|c|c|c|c|}
\hline Qty & Item Description & & er Unit & \multicolumn{2}{|c|}{ Total Cost } \\
\hline 2 & Box of 3 in wood screws 100 -ct & $\$$ & 11.69 & $\$$ & 23.38 \\
\hline 1 & $25 \mathrm{ft}$ extension cord & $\$$ & 9.68 & $\$$ & 9.68 \\
\hline 1 & $25 \times 25 \mathrm{ft}$ landscape fabric & $\$$ & 100.00 & $\$$ & 100.00 \\
\hline 20 & Landscape stakes & $\$$ & 20.00 & $\$$ & 400.00 \\
\hline 1 & 7-day digital timer & $\$$ & 24.59 & $\$$ & 24.59 \\
\hline 2 & Drip irrigation kit & $\$$ & 39.52 & $\$$ & 79.04 \\
\hline 1 & Galvanized Stock Tank & $\$$ & 90.00 & $\$$ & 90.00 \\
\hline 48 & Vertigro Stackable Growing Pot & $\$$ & 5.00 & $\$$ & 240.00 \\
\hline 12 & 1 in $x 120$ in Galvanized pipes & $\$$ & 8.65 & $\$$ & 103.80 \\
\hline
\end{tabular}




\begin{tabular}{|c|l|rr|rr|}
\hline 1 & Nutrient solution (combo) 1-gallon jug & $\$$ & 65.90 & $\$$ & 65.90 \\
\hline 1 & Irrigation PVC pipes and fittings & $\$$ & 50.00 & $\$$ & 50.00 \\
\hline 1 & Submersible water fountain pump & $\$$ & 57.00 & $\$$ & 57.00 \\
\hline 1 & Misc. material and contingency & $\$$ & 100.00 & $\$ 100.00$ \\
\hline & Total Costs & & & $\$ 1,343.39$ \\
\hline
\end{tabular}

The author is currently working closely with the regional food bank, Island Harvest, which is leasing a 1-acre plot on campus. The organization is planning to build a sustainable community garden, and the harvested vegetable produce will be distributed to local communities and hunger relief programs. Currently, this initiative is being supported by Farmingdale State College, which is supplying the irrigation system. Also, Island Harvest hosted local Boy Scout volunteers to build 8 raised beds, as seen in figures 2.1 and 2.2. Island Harvest is seeking volunteers from Farmingdale State College to build additional raised beds and maintain the garden. This opportunity can be launched as a pilot project with the Summer Scholarship Support, student volunteers from the ACT club, and faculty support from the Urban Horticulture and Design Department. This effort aligns with the objectives of the research, and it provides a chance to examine the full-scale prototyping process under a controlled environment.

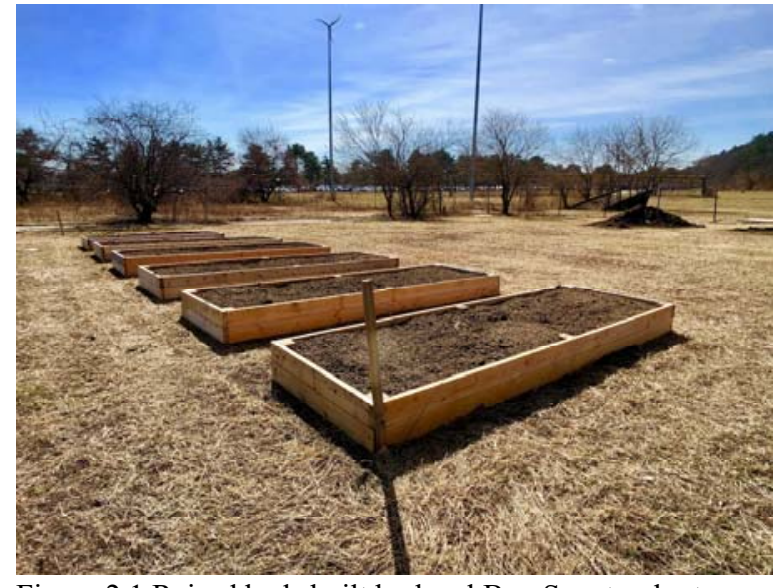

Figure 2.1 Raised beds built by local Boy Scout volunteers

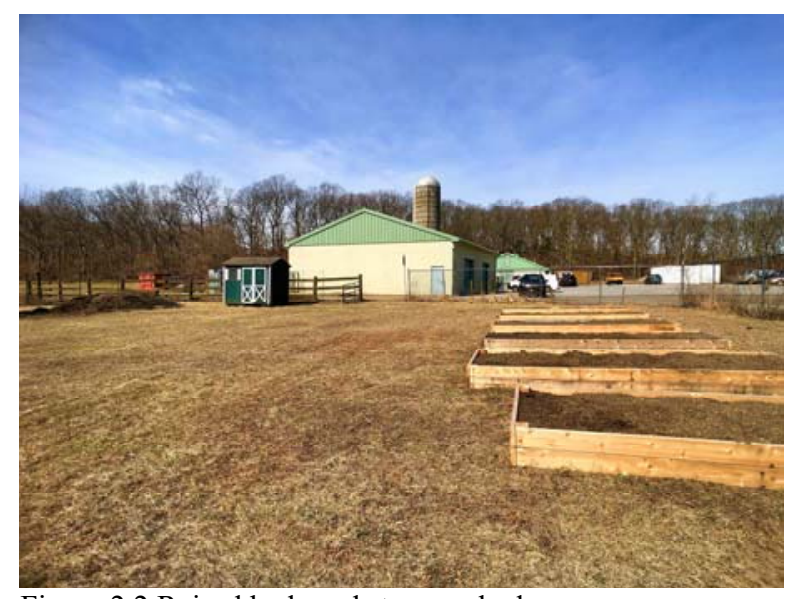

Figure 2.2 Raised beds and storage shed

Another opportunity for this pilot project is to test the educational aspect of the research. Island Harvest is spearheading diverse public-school programs that teach elementary school children about farming and the source of food. The students participate in seeding, planting, and harvesting activities in their classrooms and the school garden, as shown in figures 3.1 through 3.4. After completion of this program, the children have an in-depth understanding of crop growing and the health benefits of fresh food. The coordinator of the program will support the pilot project by educating the volunteers and providing agricultural information. A pre- and post-program survey will be distributed to measure the knowledge gained on agriculture and sustainability. These data will be a valuable reference to the educational strategy and effectiveness of the hands-on learning experience in the new proposed course. 


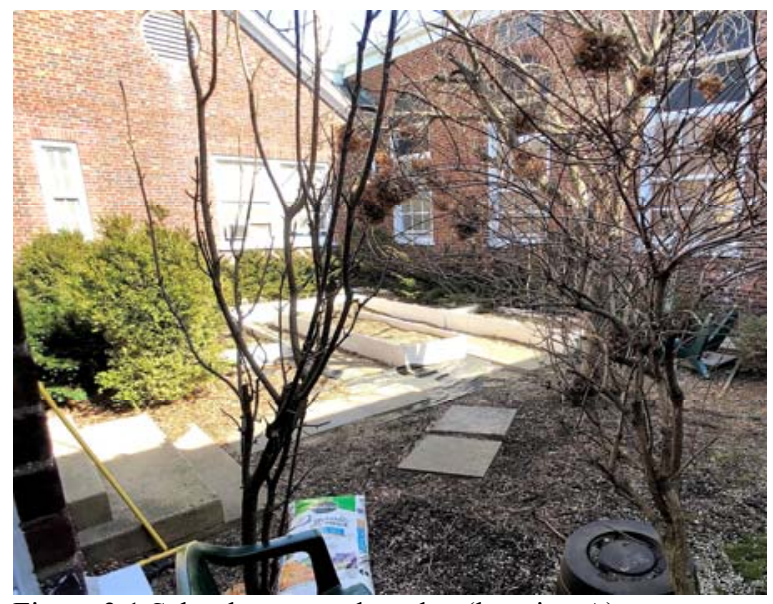

Figure 3.1 School courtyard garden (location A)

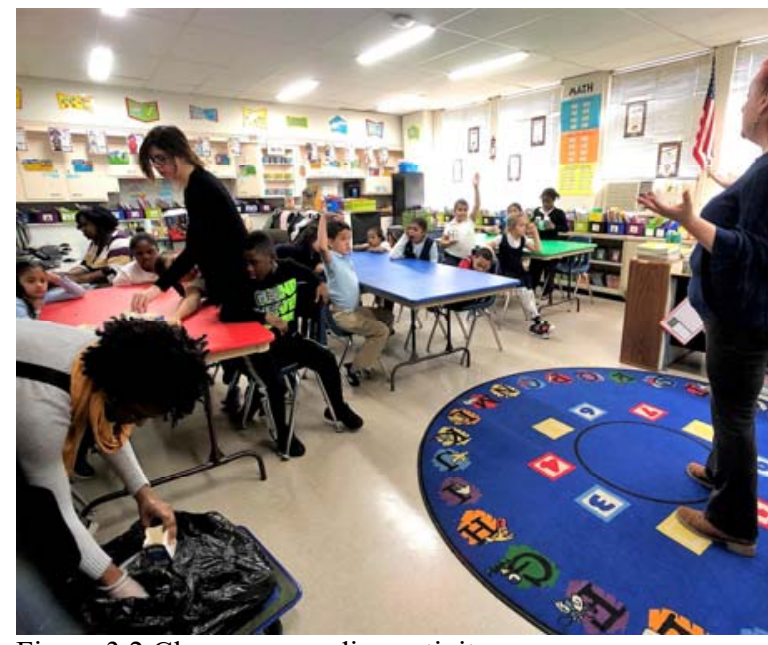

Figure 3.2 Classroom seeding activity

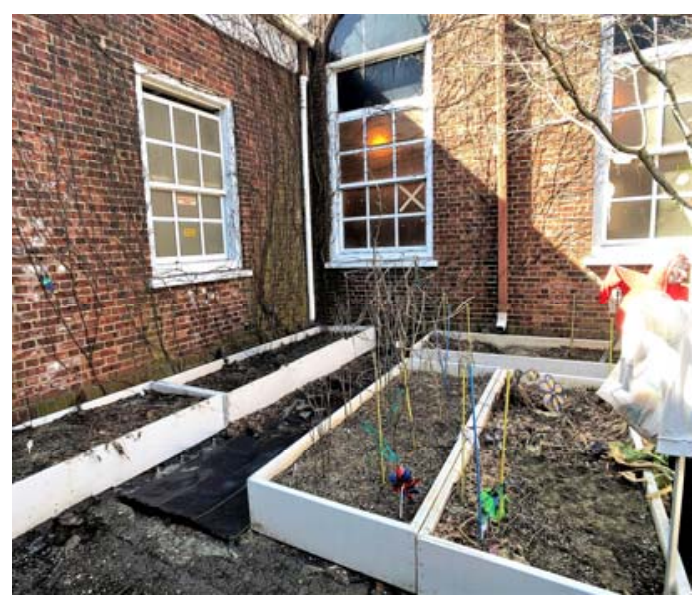

Figure 3.2 School courtyard garden (Location B)

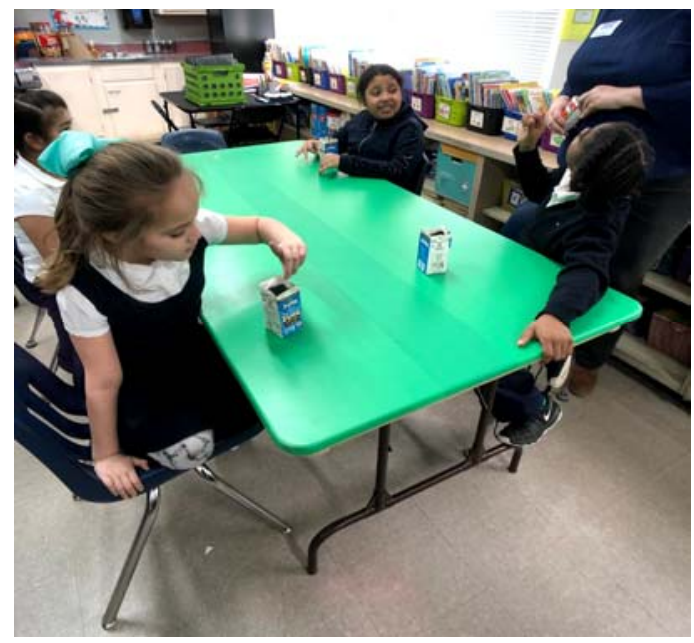

Figure 3.3 Classroom seeding activity

\section{Background research, logistics, and the next step}

To develop a framework and initiate groundwork for the new technical elective, background research requires examining the following:

- Evaluate technical courses currently offered in the curriculum and set a pre-requisite parameter for the full-scale construction process

o Apply fundamental knowledge from the freshman courses, Materials and Methods of Construction I and II,

- To make appropriate material selections - from wood, concrete, steel, and/or masonry — and evaluate advantages and disadvantages with each

- To select construction methods such as light wood framing with plates, studs, sheathing, and waterproofing with appropriate fasteners

- To employ proper means and methods for installation sequence

o Apply fundamental knowledge from the freshman course, Introduction to Graphics,

- To evaluate optimal presentation medium and strategy

- To synthesize digital instruments to externalize design concept 
- To generate visual communication with an appropriate mode of representation

o Apply fundamental knowledge from the course, Construction Design,

- To determine a proper methodological approach to assembly

- To compose appropriate documentation material

- To establish procedural parameters

o Apply fundamental knowledge from the course, Architectural Design,

- To explore design with idea formation strategy

- To analyze context and existing systems to identify the ideal location

- To perform precedent research and discern suitable design strategy

- Collaborate with the Department of Urban Horticulture and Design

o Continue the conversation on the following topics

- Timeline

- Class structure and curriculum change proposal

- Upper-level elective

- Prerequisites from both departments

- Logistics of offering the course to the students from both disciplines

- Teaching structures

- Alternating lectures

- Co-teaching

- Invited guest lecturers

- Course contents

- Agricultural knowledge

- Construction and design knowledge

- Planting selection

- Edible plants

- Diverse selection of vegetables and fruits

- Techniques

- Soil-based systems

- Hydroponic systems

- Conduct a case study of academic examples that incorporated experiential learning

o The design workshop at Parsons the New School for Design [4]

- Provides pro bono architectural services to nonprofit organizations

o The Integrated Service-Learning project at the Fashion Institute of Technology [5]

- Founded in 2013 to serve families devastated by Superstorm Sandy

o Town + Gown program at the New York City Department of Design and Construction (DDC) [6]

- An open platform research program that uses service (experiential) learning and faculty-directed research to facilitate partnerships between academics and practitioners on applied built environment research projects through the collaborative inquiry model of systemic action research

- Identify stakeholder and community organizations

o Campus Facilities Management

- To initiate a planning strategy for coordinating timelines, location, implementation, maintenance, and systems requirements 
o The Institutional Review Board

- To evaluate and approve student involvement in the process of full-scale design installation

o Island Harvest [7] and local Catholic Church

- To foster community integration, education, and volunteer-based hunger relief programs

- Investigate new emerging technology and advanced material

o bioMASON ${ }^{\circledR}$ and MycoComposite ${ }^{\mathrm{TM}}$ [8], [9]

- Reduces the energy-intensive process and offers sustainable alternatives to the traditional material by using mushroom technology

- To propose alternative material for the construction process

- Explore assessment model for evaluating student learning

o Bloom's Cognitive Taxonomy [10]

- To adopt six hierarchical levels of cognitive learning

- To draft the course material based on the assessment questions related to this model's objectives

\section{Overview of the proposed technical elective}

Course description:

This course will study the construction process through the production of drawings, models, fabrication, and a full-scale design installation. Students will make a series of presentations in a design critique format and receive technical feedback from a diverse audience. This iterative design process improves the overall quality of design and refines construction methods. This course encourages students to select and source optimal materials, within budgetary constraints, for the programmatic requirements. The course encourages group work for the design and construction process. Knowledge from Materials and Methods of Construction I and II, Introduction to Graphics, and Construction Design are applied to the semester project. The final deliverable, the full-scale installation will, demonstrate an understanding of Type V light wood construction.

Prerequisites by topic:

- Material and methods of construction

- Building structural systems

- Architectural graphics

- Information management

Course learning outcomes:

At the conclusion of the course, students attain an ability to:

- Explain fundamental construction concepts and processes

- Identify appropriate materials and construction methods

- Design a system or process to solve technical problems

- Apply an appropriate mastery of the knowledge, techniques, skills, and tools of the discipline 
Accreditation assessment:

- Student outcomes - An ability to design systems, components, processes, procedures, or programs meeting specified needs for broadly-defined engineering, technical, or scientific problems appropriate to Construction Management Engineering Technology [11]

\begin{tabular}{|l|l|l|}
\hline \multicolumn{1}{|c|}{ Performance Indicators } & \multicolumn{1}{|c|}{ Method(s) of Assessment } & Target for Performance \\
\hline $\begin{array}{l}\text { Students will be able to } \\
\text { design and install a full- } \\
\text { scale structure }\end{array}$ & $\begin{array}{l}\text { Faculty members will complete } \\
\text { the group dynamics rubric } \\
\text { assessing the collaboration of } \\
\text { class teams }\end{array}$ & $\begin{array}{l}70 \% \text { of students score } 75 \% \text { or } \\
\text { better }\end{array}$ \\
\hline
\end{tabular}

Assessment tools:

- Pre- and post-course survey

o Assess students' knowledge of sustainability and food systems before and after the pilot project

- In-class exercises

- Design presentation and critique

- Rubric for creative projects

o Knowledge and understanding

- Project definition

- Technical subjects

- Use of resources

o Application

- Principles of design

- Documentation of information

- Conclusion

Course Topics:

1. Introduction

Preliminary research

- Urban Horticulture and Design lecture

- Local community introduction

- Facilities management requirements

- Review of the construction materials and methods

- Material research

- Data collection and management

- Students' team formation

- Assessment and evaluation

2. Planning and design

- General planning

- Circulatory pattern study

- Anthropometric design studies

- Preliminary, schematic, mid, and final design review 
- Site work

- Determine morphological and dimensional parameter

- Interdisciplinary design

- Collective information

- Digital and physical models

- Scaled drawings

- Synthesize engineering of the system

- Assessment and evaluation

3. Construction

- Finalize design and construction method

- Material delivery from the supplier

- General coordination

- Orchestrate participants' roles

- Site work

- Fabrication

- Assembly of the components

- Assessment and evaluation

\section{Conclusion}

Based on the belief that experiential learning is an effective pedagogical strategy, the author is developing a framework for a new technical elective in the Department of Architecture and Construction Management. This process requires rigorous preliminary research to validate the course content and delivery method. Due to the distinctive nature of the cross-disciplinary structure, the background research for this course will include strategic planning, meticulous timeline coordination, simulation of multiple scenarios with a pilot project, and orchestration of student and public involvement. The documentation of this process is an effort to provide a standardized and scalable model for other academic institutions to adopt. The instructional strategy has evolved over time, striving to improve student learning, but the most in-depth understanding comes from hands-on experience and applying knowledge in a real-world environment, particularly when it benefits others.

\section{References}

[1] A. A. Sorensen, J. Freedgood, J. Dempsey and D. M. Theobald, "Farms Under Threat: The State of America's Farmland," American Farmland Trust, Washington, DC, 2018.

[2] United States Department of Agriculture, Economic Research Service, "Beginning Farmers and Age Distribution of Farmers," United States Department of Agriculture, [Online]. Available: https://www.ers.usda.gov/topics/farm-economy/beginning-disadvantaged-farmers/beginningfarmers-and-age-distribution-of-farmers/. 
[3] Arcadia University, "Alternative Spring Break," Arcadia University, [Online]. Available: https://www.arcadia.edu/life-arcadia/activities-organizations/community-civic-engagement/annualevents/alternative-spring.

[4] School of Constructive Environment, "ABOUT DESIGN WORKSHOP," Parsons New School for Design, [Online]. Available: http://sce.parsons.edu/special-projectindividual/?type=des_workshop_event.

[5] Interior Design, "Integrated Service-Learning Project," Fashion Institute of Technology, [Online]. Available: http://www.fitnyc.edu/interior-design/service-learning/index.php.

[6] Department of Design and Construction, "Town+Gown," Department of Design and Construction, [Online]. Available: https://www1.nyc.gov/site/ddc/about/town-gown.page.

[7] Island Harvest, "Island Harvest," Island Harvest, [Online]. Available: https://www.islandharvest.org/.

[8] bioMason, "bioMason," bioMason, [Online]. Available: https://biomason.com/.

[9] Ecovative, "MycoComposite," Ecovative, [Online]. Available: https://ecovativedesign.com/mycocomposite.

[10] B. Bloom, Taxonomy of Educational Objectives: The Classification of Educational Goals, New York: David McKay Company, 1956.

[11] ABET, "ACCREDITATION POLICY AND PROCEDURE MANUAL," ABET, Baltimore. 